This item was submitted to Loughborough's Research Repository by the author.

Items in Figshare are protected by copyright, with all rights reserved, unless otherwise indicated.

\title{
Wearable and meshed wideband monopole antennas and their interactions with the human body
}

PLEASE CITE THE PUBLISHED VERSION

https://doi.org/10.1049/iet-map.2018.5862

\section{PUBLISHER}

Institution of Engineering and Technology (IET)

VERSION

AM (Accepted Manuscript)

\section{PUBLISHER STATEMENT}

This paper is a postprint of a paper submitted to and accepted for publication in IET Microwaves, Antennas \& Propagation and is subject to Institution of Engineering and Technology Copyright. The copy of record is available at the IET Digital Library.

\section{LICENCE}

CC BY-NC-ND 4.0

\section{REPOSITORY RECORD}

Rayner, Phoebe, Shiyu Zhang, Darren Cadman, J. C. Vardaxoglou, and William Whittow. 2019. "Wearable and Meshed Wideband Monopole Antennas and Their Interactions with the Human Body". figshare. https://hdl.handle.net/2134/9929693.v1. 


\title{
Wearable and meshed wideband monopole antennas and their interactions with the human body
}

\author{
Phoebe Rayner ${ }^{1}$, Shiyu Zhang ${ }^{1}$, Darren Cadman ${ }^{1}$, J(Yiannis) C. Vardaxoglou ${ }^{1}$, Will Whittow ${ }^{1 *}$ \\ ${ }^{1}$ Wolfson School of Mechanical, Electrical and Manufacturing Engineering, Loughborough University, UK \\ *w.g.whittow@lboro.ac.uk
}

\begin{abstract}
This paper considers a wideband monopole antenna and its interactions with different separations from the human body phantom over a wide frequency. A meshed alternative version has also been developed which has similar performance to the circular wideband monopole antenna but requires less material. The SAR and efficiency of this antenna has been analysed as a function of separation distance and frequency. The mesh design has been fabricated by using embroidery and 3D printing techniques.
\end{abstract}

\section{Introduction}

The world is dependent on wireless connectivity and intelligent connected devices will become increasingly prevalent. It is widely predicted that by 2020 , there will be 30 billion connected devices in addition to mobile phones. This means antennas will be required in different shapes and size and fabricated using different technologies and materials. A comprehensive literature review including manufacturing techniques of wearable antennas can be found in [1]. Wearable antennas have potential applications in a range of sectors including military, aerospace, fashion and space [2] [3].

Different fabrication techniques have their own advantages and disadvantages. Inkjet printed dipole antennas were fabricated in [4]. The gain and efficiency increased as the antenna was moved further away from the lossy body. The paper also showed some detuning when it was bent around the arm. Further examples of wearable antennas can be found in [5]-[9].

Patch antennas are often considered as possible candidates for wearable antennas. However, they are very narrow band. Wideband wearable antennas can be created by having a partial groundplane below the monopole [10]-[18]. Zhang et al. [19]-[21] embroidered antennas using conductive threads. Embroidery can be aesthetically integrated into clothing and manufactured as individual unique elements or mass-manufactured.

The absence of the groundplane for wideband antennas means that when the antenna is placed in close proximity to the human body, the specific absorption rate (SAR) must be considered [22]-[24].

The disadvantage of embroidery is that the thread can be expensive, approximately $£ 0.5$ per metre and even small antennas can use several metres of thread. The cost of material is also an issue for inkjet printing. In addition to this using a continuous design compared to a meshed design will increase the fabrication time. Furthermore, a meshed design may feel more comfortable and allow moisture to pass which will increase the breathability.

This paper is an invited extension of the preliminary conference paper [25]. The original paper considered a continuous circular monopole antenna that exhibited wideband behaviour. This extended paper contains new simulation results and analysis in Section 3 and examines the behaviour in terms of S11, Gain and efficiency of the wideband antenna at different distances from the body. Section 4 develops a new design which is a meshed version. The SAR has been analysed along with the allowable transmitted powers. Finally, the meshed antenna has been embroidered and 3D printed in Section 4.4 and 4.5, respectively.

\section{Circular Monopole and Phantom Geometry}

The geometry of the antenna is shown in Fig. 1. It consists of a partial ground plane $(20 \mathrm{~mm} \times 55 \mathrm{~mm})$; a $0.53 \mathrm{~mm}$ thick denim substrate layer; and circular monopole with a $55 \mathrm{~mm}$ diameter that is fed by a $1.7 \mathrm{~mm}$ wide 50 -ohm transmission line. All simulation results were carried out using EMPIRE XPU electromagnetic software. The metal sections were 30 micron thick copper. The dielectric properties of the denim were $\varepsilon_{\mathrm{r}}=1.8, \tan \delta=0.07$ and were measured using a split post dielectric resonator [26]. The design was optimised in [25] to achieve a wideband response up to $60 \mathrm{GHz}$ both in free space and on and near phantoms.

The monopole antenna was placed on the stomach of an anatomical phantom called "Ella" which is a voxel model of a 26-year-old female. This is available via the ITIS Foundation: https://itis.swiss/virtual-population/virtualpopulation/overview

Fig. 2 shows that the antenna is not exactly parallel to the surface of the body. When the antenna was placed " $0 \mathrm{~mm}$ " away from the body, this means the top of was adjacent to the human body model, while the bottom of the antenna had a small separation. The feedpoint of the antenna was below the antenna itself and pointed towards the feet. Note that the whole human body was not simulated to save computational resources. The truncated phantom is shown in Fig.2. In this paper, the dielectric properties of the phantom were set to the properties at $2.4 \mathrm{GHz}$. This approximation was found to have minimal effects to the S11 or efficiency in [25]. In this current paper the antenna was moved away 10 and $20 \mathrm{~mm}$ away from the anatomical phantom to assess the effect on the efficiency and the S11. 


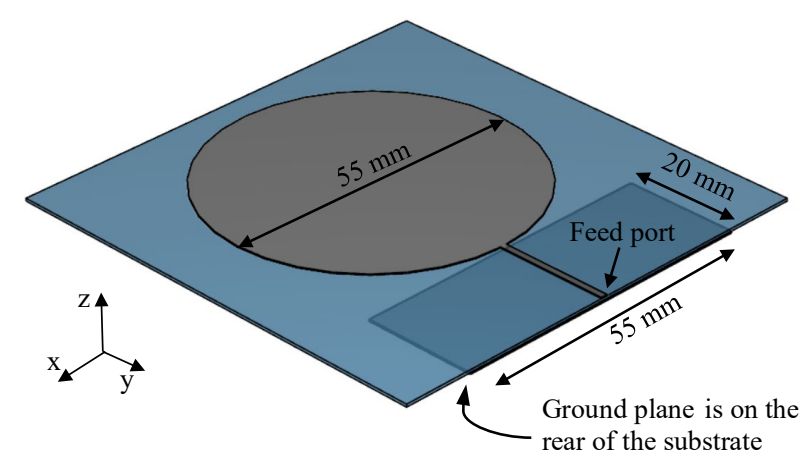

Fig. 1. Dimensions and design of the circular monopole antenna
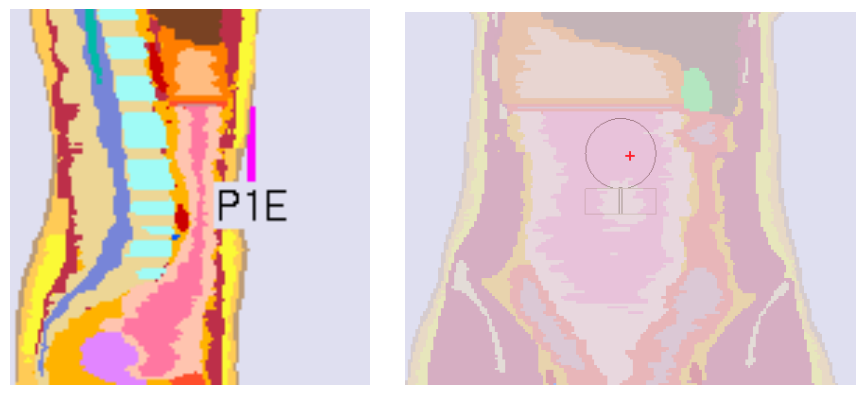

Fig. 2. Antenna location on the stomach of the truncated phantom. "P1E" in the left-hand image represents the excitation. Note, the righthand picture has been made partially transparent to show the antenna location clearly.

\section{Circular Monopole Results}

\subsection{Simulated Results}

The simulated S11 results are shown in Fig.3. When the antenna was in free space the S11 was generally below $10 \mathrm{~dB}$ for frequencies above $1.3 \mathrm{GHz}$ except for a small section at $3.8 \mathrm{GHz}$ where the $\mathrm{S} 11$ is approximately $-9.5 \mathrm{~dB}$. This specific frequency is still reasonably well matched in practical terms. There are always trade-offs across the frequency band as improving the S11 at one frequency affects the S11 at other frequencies. When the top of the antenna was placed $0 \mathrm{~mm}$ from the torso, the dielectric loading reduced the lower frequency point where the $\mathrm{S} 11$ was below - $10 \mathrm{~dB}$ to approximately $0.8 \mathrm{GHz}$ however this comes at the cost of reduced efficiency as analysed later in this section. When the antenna was moved 10 or $20 \mathrm{~mm}$ away from the torso as might naturally occur in loose fitting clothing, the antenna remained well matched and the worst $\mathrm{S} 11$ values had a magnitude of approximately $-7 \mathrm{~dB}$ at $2.2 \mathrm{GHz}$.

Fig. 3 shows that generally the antenna is reasonably well matched over a wide frequency band with or without the phantom and with different separation distances.

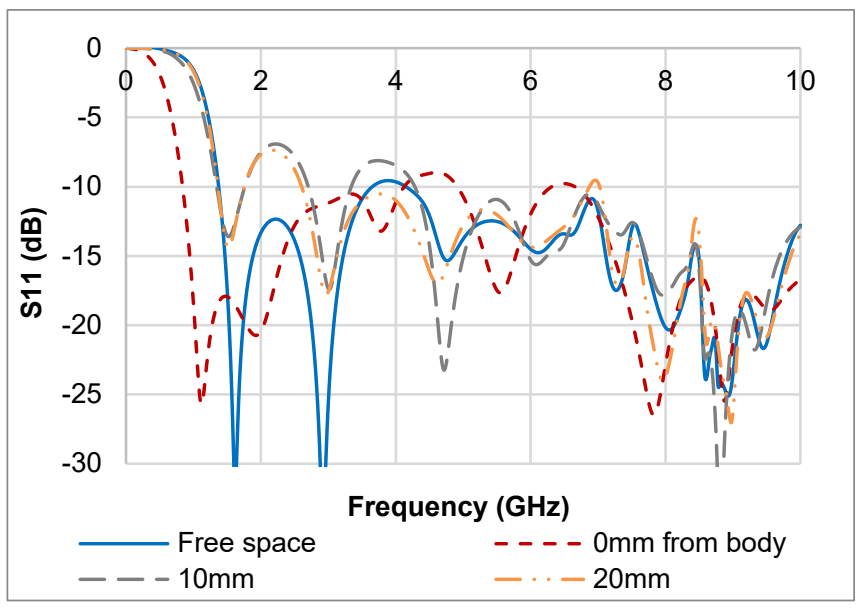

Fig. 3. Simulated S11 of the monopole antenna in free space and 0,10 and $20 \mathrm{~mm}$ away from the body torso

Fig. 4 shows the simulated total efficiency over a wide frequency range for the antenna placed at different distances away from the torso. The total efficiency results in Fig. 4 include the $\mathrm{S} 11$ and hence this explains the low efficiency values at $1 \mathrm{GHz}$. At $1.8 \mathrm{GHz}$ and above the radiation efficiency closely approximates the total efficiency. Note, when the antenna was $0 \mathrm{~mm}$ from the phantom, there was a gap between the bottom of the antenna and the torso. When the antenna was $0 \mathrm{~mm}$ away the efficiency is less than $40 \%$ for all frequencies up until $10 \mathrm{GHz}$ but generally increases with frequency as the bottom of the antenna was moved electrically further from the torso. Moving the antenna away from the torso or/and increasing the frequency tended to increase the efficiency. However, above $5 \mathrm{GHz}$ there is little difference in the efficiency when the antenna is 10 or 20 $\mathrm{mm}$ away from the phantom.

As a comparison the antenna was simulated on a cuboid of body equivalent properties $\left(\varepsilon_{\mathrm{r}}=35.1, \tan \delta=0.468\right)$. When the back of the ground plane antenna was touching the cuboid phantom, the total efficiency was below 5\% at all frequencies. This would represent the worst-case scenario in terms of the interaction of the antenna and the body. When the antenna was moved 10 or $20 \mathrm{~mm}$ away from the cuboid phantom, the results closely replicated the trend of the results on the phantom in Fig. 4 with total efficiency values that converged to 70 to $80 \%$ above $5 \mathrm{GHz}$.

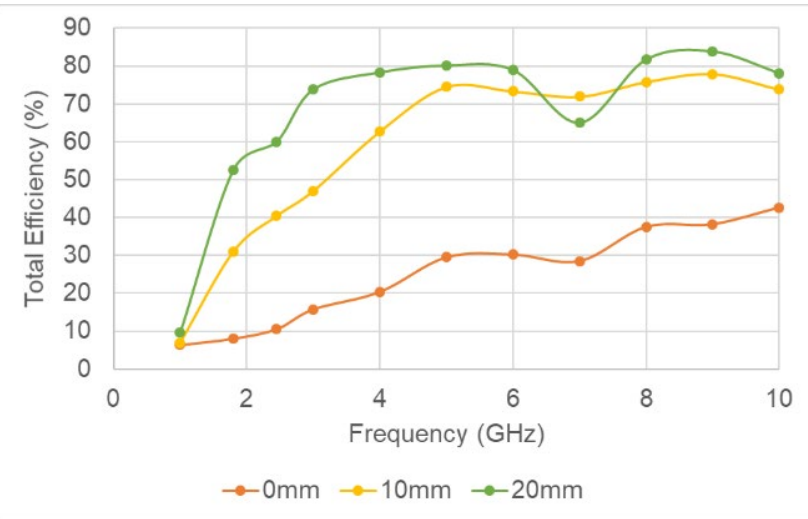

Fig. 4. Total efficiency of monopole antenna 0, 10 and 20 $\mathrm{mm}$ away from the phantom 


\subsection{Measured Results}

The monopole was fabricated using a thin flexible GTS copper sheet as the ground plane which was glued to the denim substrate with a spray adhesive. The feedline and circular monopole were made from Nora Dell conducting fabric. An SMA connector was then soldered between the feedline and the ground plane, see Fig. 5. The S11 was measured when the monopole was on the stomach of a real person wearing a shirt. Polystyrene was used to separate the antenna 2, 12 and $22 \mathrm{~mm}$ away from the body. This replicated a padded jacket or clothing that was hanging away from the body. The measured antenna exhibited a wideband response but was not as well matched as the simulated antenna, see Fig. 6 . The measured $\mathrm{s} 11$ was below $-6 \mathrm{~dB}$ for all separations and for all frequencies.
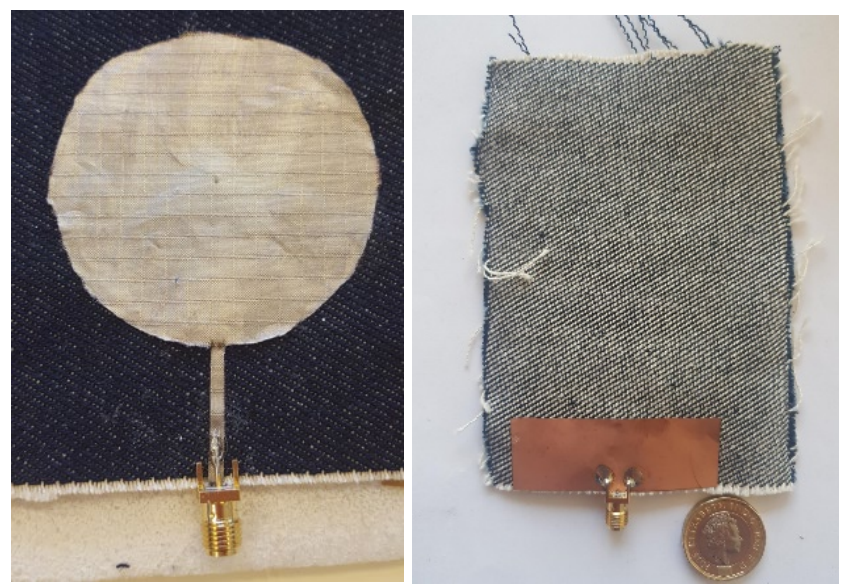

Fig. 5. Fabricated circular monopole antenna: (front and back)

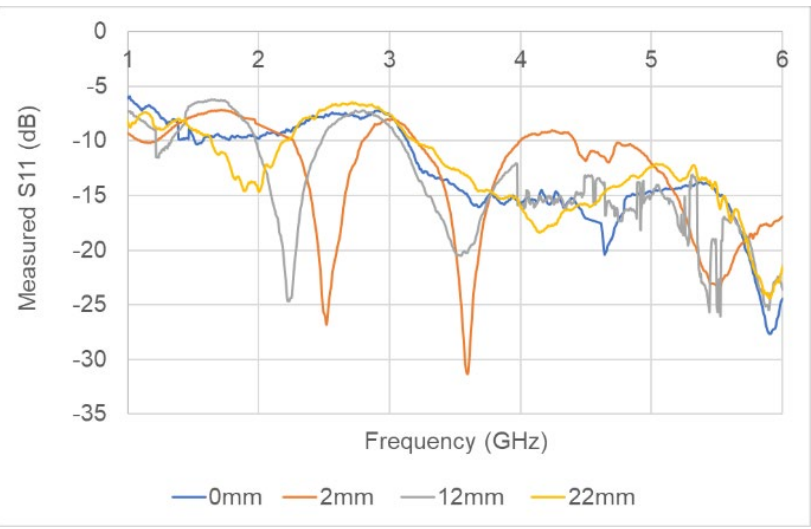

Fig. 6. Measured S11 of circular monopole antenna at different distances from an actual person

\section{Meshed Monopole Antenna}

\subsection{Geometry}

Meshed designs were considered to reduce the quantity of metal required [27]. This potentially saves time for embroidery and inkjet printing fabrication. It also makes the antenna more flexible and more comfortable for the wearer. Several different configurations were examined. The optimum design is shown in Fig. 7. This consists of three thin circular rings with external diameters of 55, 45 and $18 \mathrm{~mm}$; plus, three vertical and three horizontal lines. All lines had a $1 \mathrm{~mm}$ thickness. Without the vertical and horizontal lines, the antenna lost its wideband attributes. Placement of the inner two circles improved the matching at critical frequencies. It was found that meshing the ground plane did not give a wideband response and hence the ground plane was left as a continuous block of $55 \times 20 \mathrm{~mm}$.

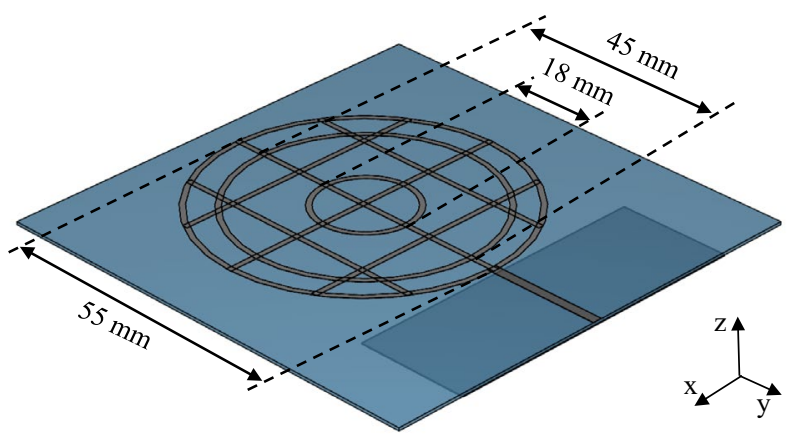

Fig. 7. Geometry of meshed monopole antenna

\subsection{Simulated Results}

The simulated S11 of the meshed monopole is shown in Fig. 8. The meshed version had a similar S11 compared to the complete circular monopole and was generally well matched until $60 \mathrm{GHz}$.

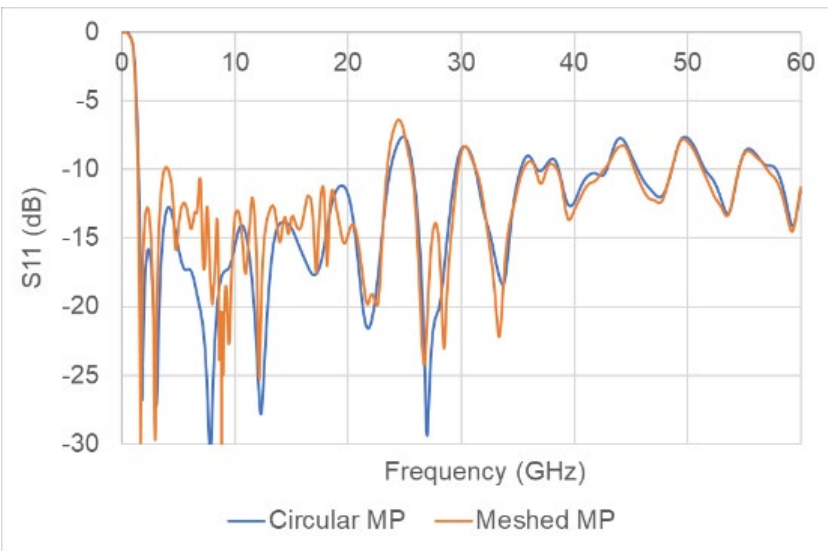

Fig. 8. Simulated S11 of circular and meshed monopole antennas in free space

The simulated total efficiency of the meshed monopole is shown in Fig. 9. When the top of the meshed version was placed $0 \mathrm{~mm}$ away from the body phantom the total efficiency increased with increasing frequency. The results were very similar to the circular monopole shown in Fig. 4. As an alternative, the effect of different fabrication possibilities was examined. The thickness of the metallisation was reduced to 1 micron and the conductivity was reduced to 
$1 \mathrm{M} \mathrm{S} / \mathrm{m}$. This approximately emulates metallization thickness and the material conductivity in inkjet printing or embroidery [28]. The results are labelled "Em" in Fig. 9. When the embroidered antenna was in free space the total efficiency was approximately two-thirds of the copper version across the whole frequency range considered. Therefore, using a thinner metal with a lower conductivity does decrease the efficiency as expected but the antenna would still be effective as a radiating device. Similarly, when the meshed version was placed $0 \mathrm{~mm}$ from the body the efficiency was reduced by the same fraction compared to the copper version near the phantom.

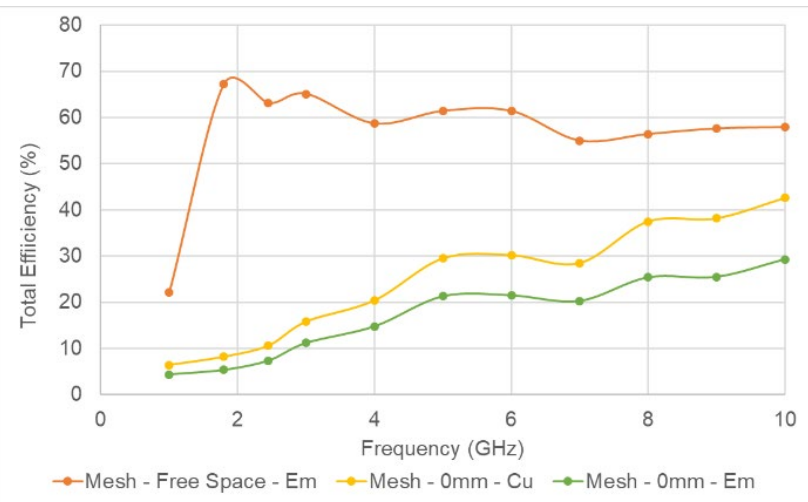

Fig. 9. Simulated efficiency for embroidered (Em) meshed antenna in free space compared to the copper $(\mathrm{Cu})$ and embroidered antennas $0 \mathrm{~mm}$ from the phantom

Note the simulation of the meshed monopole on-body and for the specific absorption rate in this paper use the copper metal thickness of 30 microns and conductivity of 5.8 $\times 10^{7} \mathrm{~S} / \mathrm{m}$. The directivity and realised gain of the meshed monopole are shown in Fig.10 and Fig. 11. Note, the gain includes the reflection efficiency. The low gain values at 1 $\mathrm{GHz}$ are because the antenna was not well matched when placed away from the body and hence the reflection efficiency is poor (see Fig. 3); when the antenna was close to the body, the reflection efficiency is higher, but the radiation efficiency is low. Note, at $1 \mathrm{GHz}$, the antenna is close to the body in terms of wavelengths. The human body acts as a lossy ground plane and increases the directivity to approximately 8 $\mathrm{dBi}$. The directivity is relatively constant with frequency. The patterns in Fig. 11 show that the beam is tilted upwards which is due to the stomach of the phantom not being exactly vertical.

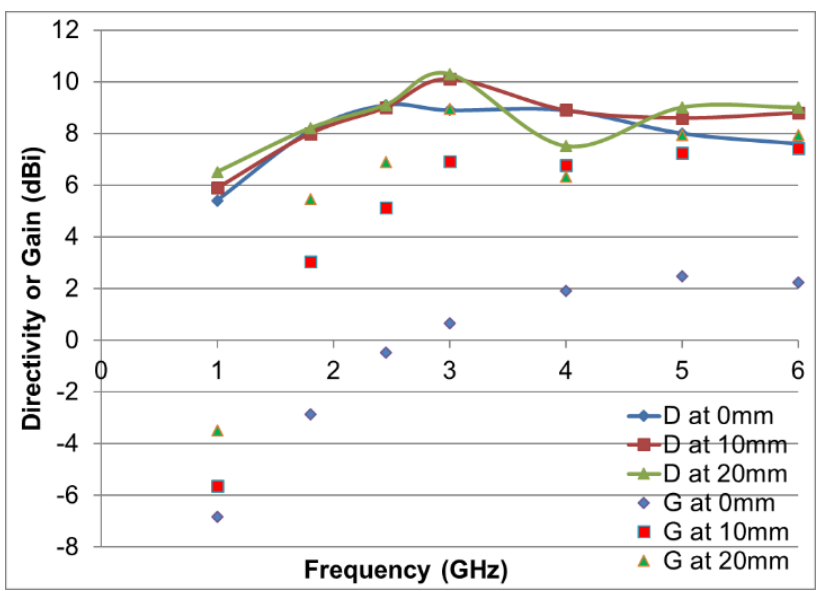

Fig. 10. Simulated directivity and gain of the meshed monopole at different distances from the phantom. Note, the simulated values were only taken at the specific frequencies were the markers are; the lines for Directivity have been added to enhance the visual readability of the graph.
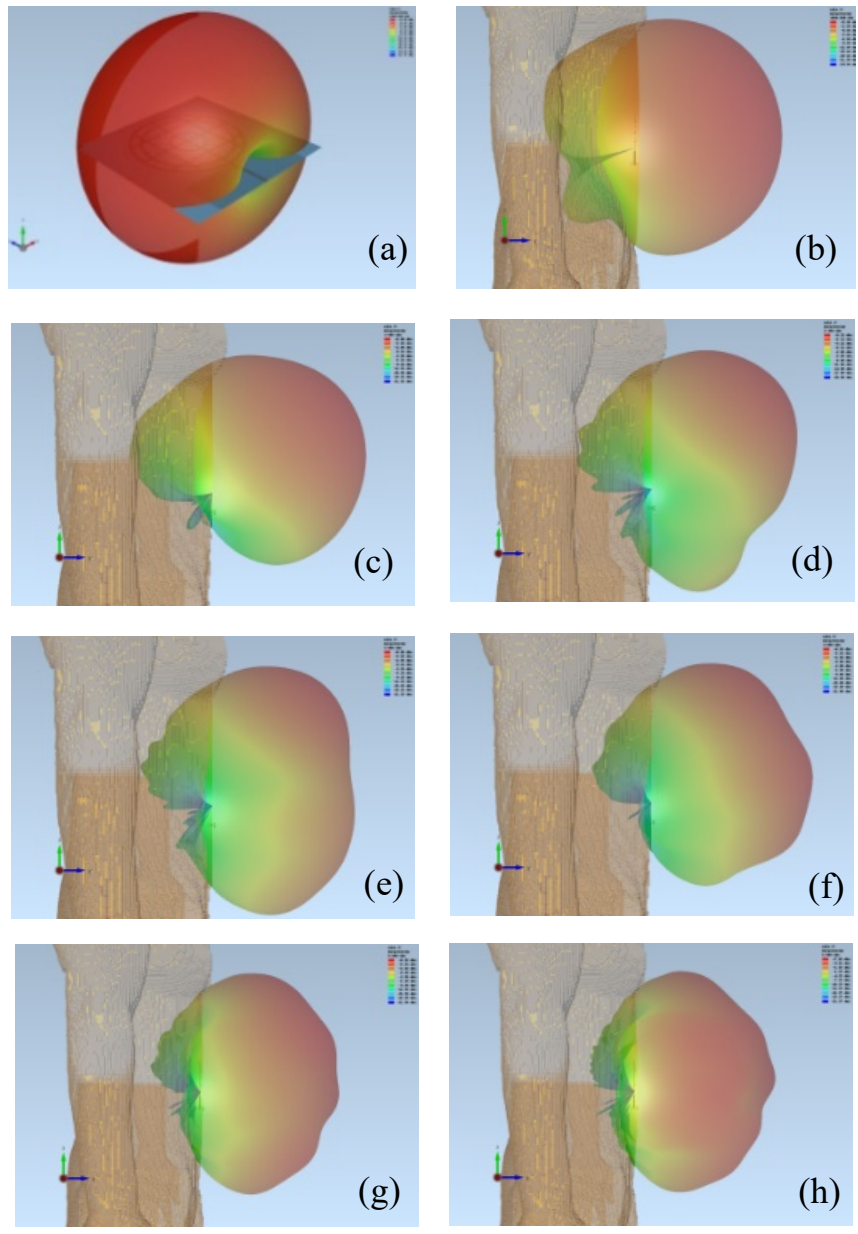

Fig. 11. Simulated directivity of meshed monopole: (a) free space at $1 \mathrm{GHz}$ showing a dipole like pattern. $0 \mathrm{~mm}$ from phantom: (b) $1 \mathrm{GHz}$; (c) $1.8 \mathrm{GHz}$; (d) $2.45 \mathrm{GHz}$; (e) $3 \mathrm{GHz}$; (f) $4 \mathrm{GHz}$; (g) $5 \mathrm{GHz}$; (h) $6 \mathrm{GHz}$ 


\subsection{Specific Absorption Rates}

The specific absorption rate (SAR) is an important metric when considering wearable antennas. The local SAR normalised to $1 \mathrm{~W}$ in a cross section through the torso is shown in Fig. 12. At higher frequencies the electric fields penetrate less deeply into the human body due to the electrical skin depth effects. This means the SAR at higher frequencies is much smaller several centimetres into the body. Table 1 shows the maximum $1 \mathrm{~g}$ and $10 \mathrm{~g}$ SAR as a function of frequency and distance away from the torso. Note the $1 \mathrm{~g}$ and $10 \mathrm{~g}$ values are normalised to $1 \mathrm{~W}$ which is likely to be a much higher power level than would be used in practice. The table also shows the maximum power levels that could be transmitted without breaking the SAR regulations (IEEE, $1 \mathrm{~g}$, USA: $2 \mathrm{~W} / \mathrm{kg}$; ICNIRP, $10 \mathrm{~g}$, Europe: $1.6 \mathrm{~W} / \mathrm{kg}$ ). If the $1 \mathrm{~g}$ and $10 \mathrm{~g} \mathrm{SAR}$ are higher, less power can be legally transmitted. For the worst-case scenario of the antenna being close to the body, the transmit power would be limited to 0.07 W. Although it could be higher for controlled environments or military personnel.
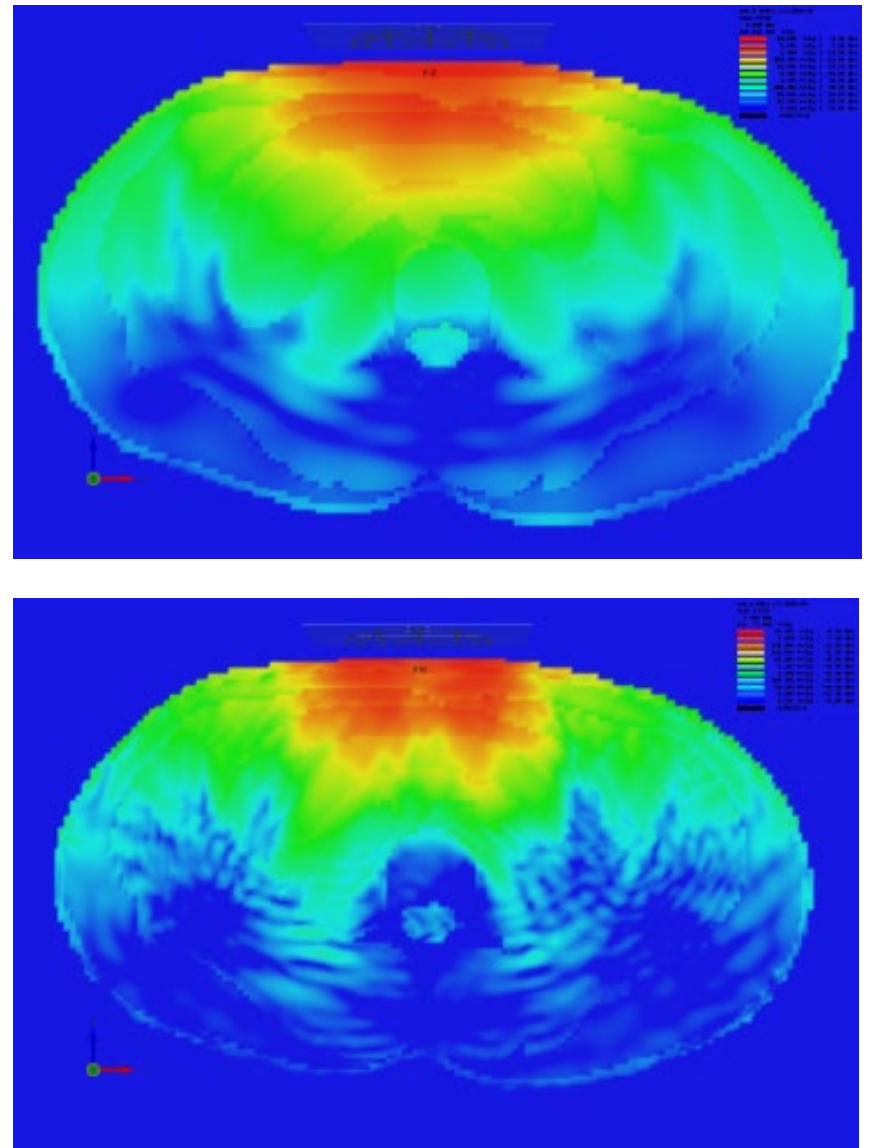

Fig. 12. Local SAR (W/kg) for meshed monopole $0 \mathrm{~mm}$ from the phantom in a cut half way up the monopole at (a) $1.8 \mathrm{GHz}$ and (b) $5.8 \mathrm{GHz}$
Table $11 \mathrm{~g}$ and $10 \mathrm{~g}$ SAR in the phantom with the meshed monopole antenna with input power of $1 \mathrm{~W}$; and maximum permissible power levels to not break the SAR regulations

\begin{tabular}{cccccc}
\hline $\begin{array}{c}\text { Freq } \\
(\mathrm{GHz})\end{array}$ & $\begin{array}{c}\text { Distance } \\
\text { from } \\
\text { body } \\
(\mathrm{mm})\end{array}$ & $\begin{array}{c}\text { Max } \\
1 \mathrm{~g} \\
\text { SAR } \\
(\mathrm{W} / \mathrm{kg})\end{array}$ & $\begin{array}{c}\text { Max } \\
10 \mathrm{~g} \\
\text { SAR } \\
(\mathrm{W} / \mathrm{kg})\end{array}$ & $\begin{array}{c}\text { Max } \\
\text { Power: } \\
\text { IEEE } \\
(\mathrm{W})\end{array}$ & $\begin{array}{c}\text { Max } \\
\text { Power: } \\
\text { ICNIRP } \\
(\mathrm{W})\end{array}$ \\
\hline 1.8 & 0 & 20.3 & 13.8 & 0.08 & 0.15 \\
1.8 & 10 & 13.0 & 7.8 & 0.12 & 0.26 \\
1.8 & 20 & 5.9 & 3.6 & 0.27 & 0.56 \\
2.45 & 0 & 23.4 & 15.1 & 0.07 & 0.13 \\
2.45 & 10 & 13.6 & 8.0 & 0.12 & 0.25 \\
2.45 & 20 & 6.0 & 3.8 & 0.27 & 0.52 \\
5.8 & 0 & 21.6 & 7.2 & 0.07 & 0.28 \\
5.8 & 10 & 2.5 & 1.4 & 0.64 & 1.47 \\
5.8 & 20 & 1.4 & 0.8 & 1.11 & 2.50 \\
& & & & &
\end{tabular}

\subsection{Embroidered Meshed Monopole Antenna}

The embroidered meshed monopole was fabricated using a specialist digital embroidery machine, Brother PR1000e, see Fig. 13. Amberstrand conducting thread was used. This is composed of a polymer core with a conducting layer on the outside. The metallisation is thin and is a mixture of silver and nickel and hence has a lower conductivity than bulk silver. A small section of thin copper material was used as the ground plane which was glued to the back of the denim, see Fig. 14. An SMA connectors was attached using low temperature solder. The measured results are shown in Fig.15. It can be seen that the embroidered antenna does not have exactly the same wideband response. Fig. 14 shows that the embroidery technique is composed of many individual threads rather than being a continuous surface. The transmission line is particularly sensitive and changes in the interconnection between threads here will change the S11. Additionally, it is hard to guarantee that the conducting threads are electrically connected at the mesh intersections. 


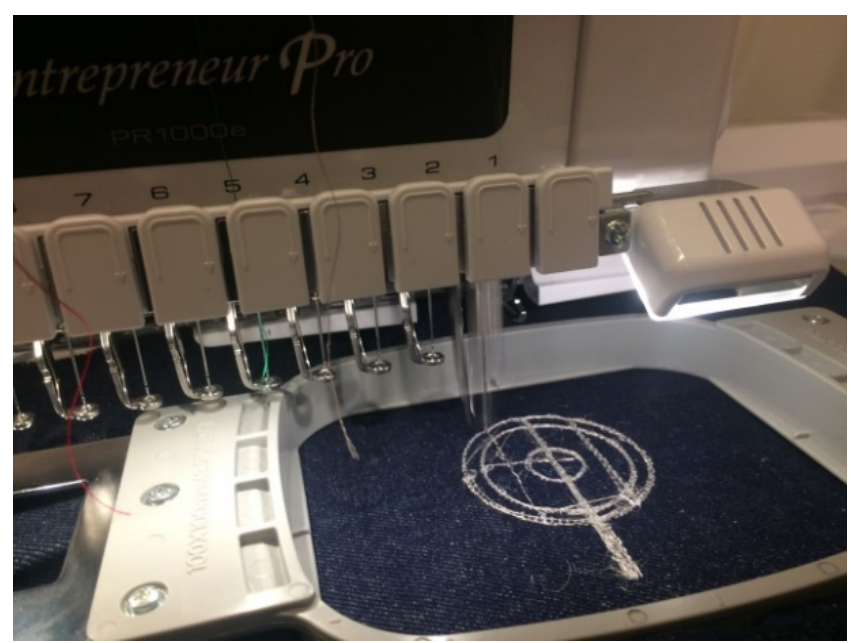

Fig. 13. Meshed monopole being embroidered
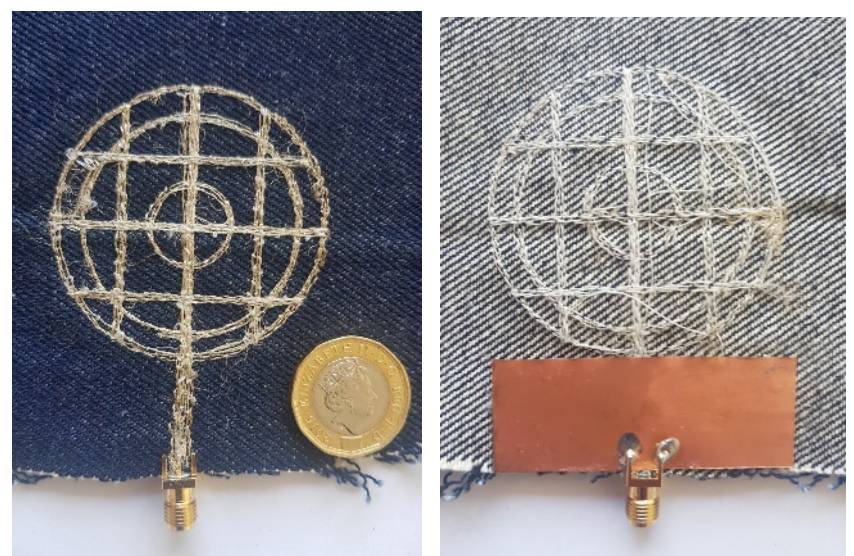

Fig. 14. Embroidered meshed monopole antenna: front and back

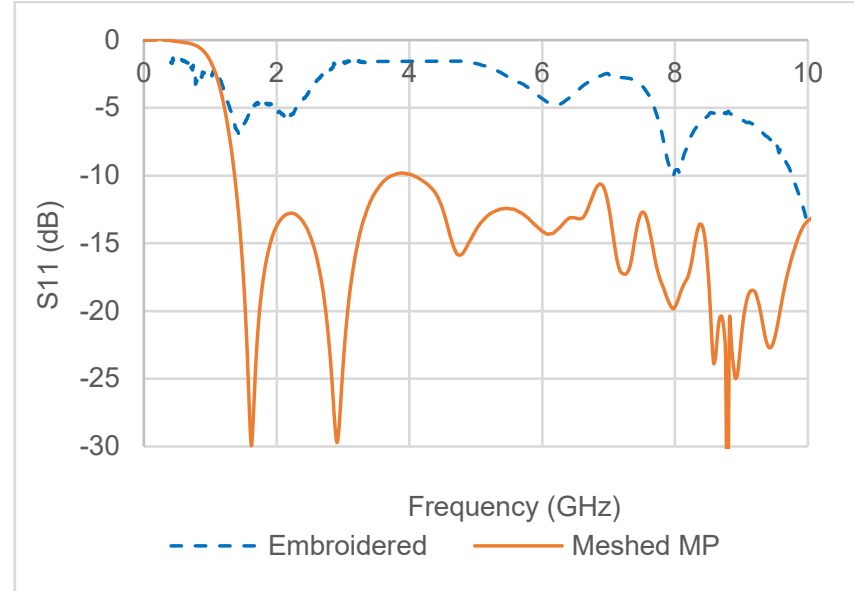

Fig. 15. Measured S11 of embroidered meshed monopole antenna (blue) compared to simulated (red)

\subsection{D Printed Meshed Monopole Antenna}

The meshed monopole antenna was fabricated by using a Voxel8 3D printer to verify the design. The Voxel8 Developer's Kit is a multi-material 3D Printer, which allows extruding thermoplastic and silver conductive ink through two independent print heads. It offers extra design of freedom of creating embedded circuits and RF components additive manufacturing techniques. Fig. 16 shows the meshed monopole antenna is being 3D printed in a layer by layer process. The finished antenna with attached SMA connector is shown in Fig. 17. The silver layer had a thickness of $0.2 \mathrm{~mm}$, with the resistivity of $\sim 3.0 \times 10^{-7} \Omega \cdot \mathrm{m}$ [29]. Thermal plastic PLA was used for the substrate with the relative permittivity of 2.75 , loss tangent of 0.008 [30] and thickness of $0.5 \mathrm{~mm}$. The ground plane was made by a small section of thin copper tape that was similar to the embroidered monopole antenna.

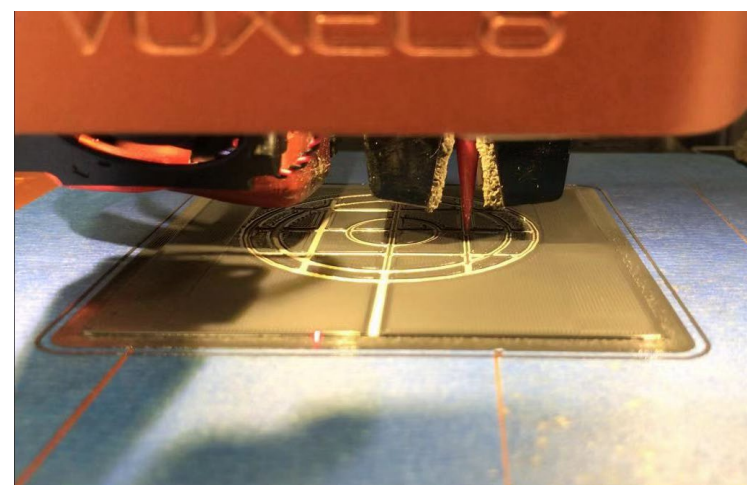

Fig. 16. Meshed monopole being 3D printed

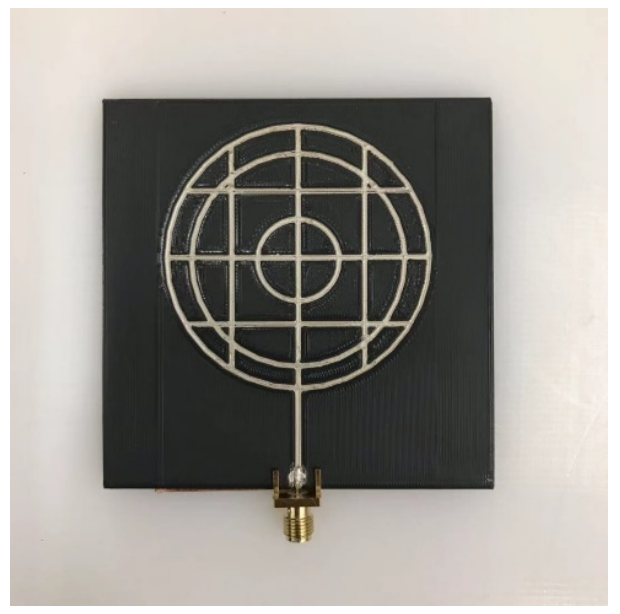

Fig. 17. 3D printed meshed monopole antenna

The measured $\mathrm{S} 11$ of the $3 \mathrm{D}$ printed meshed monopole antenna is shown in Fig.18, compared with the simulated result that had the meshed monopole with PLA substrate and silver paste as the conductor. The results show that the good agreement between measurement and simulation, with the $\mathrm{S} 11$ generally below $-10 \mathrm{~dB}$ for frequencies above $1.6 \mathrm{GHz}$. 


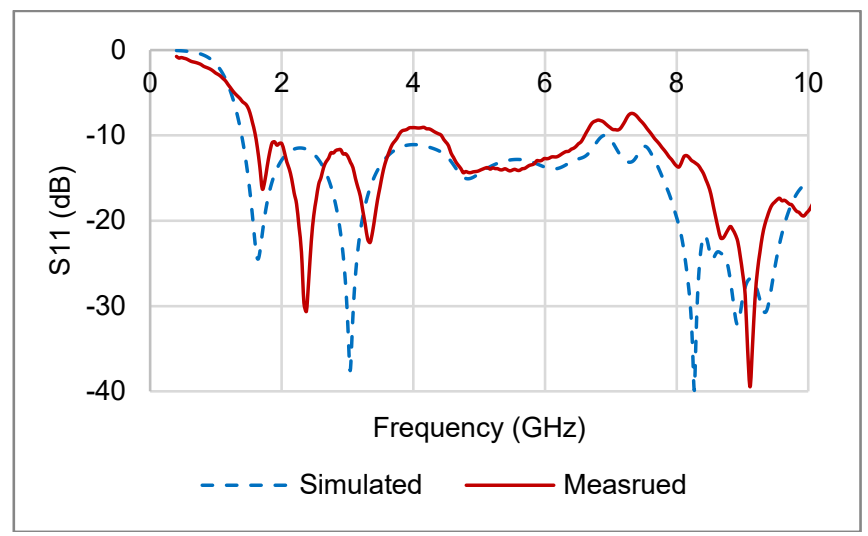

Fig. 18. Measured S11 of 3D printed meshed monopole antenna, compared with simulation

The 3D printed meshed monopole antenna was measured in a spherical near field chamber. The measured directivity radiation pattern is shown in Fig.19. Due to the limited frequency range of standard gain antenna, the measured results started from $4 \mathrm{GHz}$. Although the measured patterns were slightly distorted due to the positioner in the anechoic chamber, the measured patterns generally agreed well with the simulation results. The measured realised gain and directivity across the frequency band from 4 to $10 \mathrm{GHz}$ is shown in Fig.20. The reduced gain might be due to the low conductivity of the epoxy that was used for affixing the SMA connector. The measured total efficiency of the antenna ranged from approximately $55.6 \%$ to $86.9 \%$.
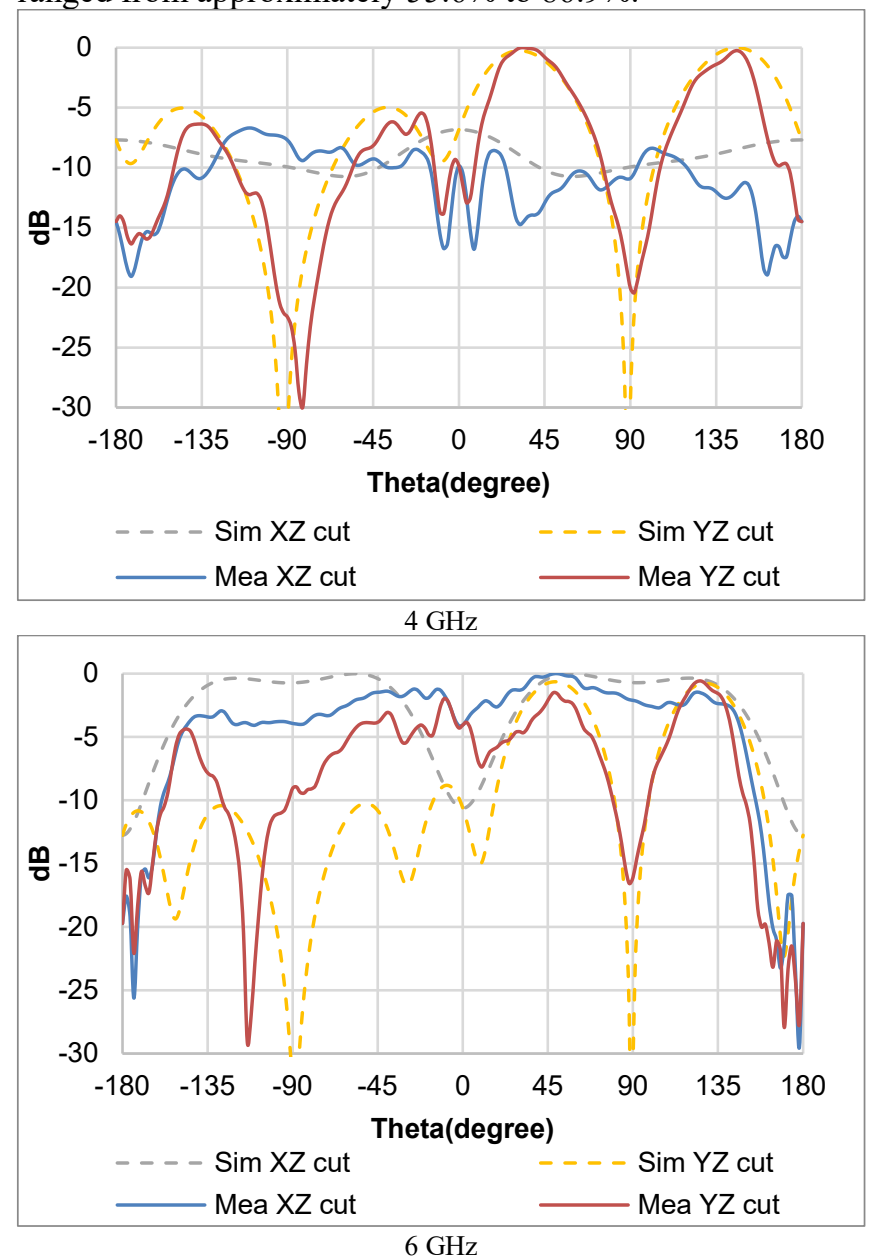
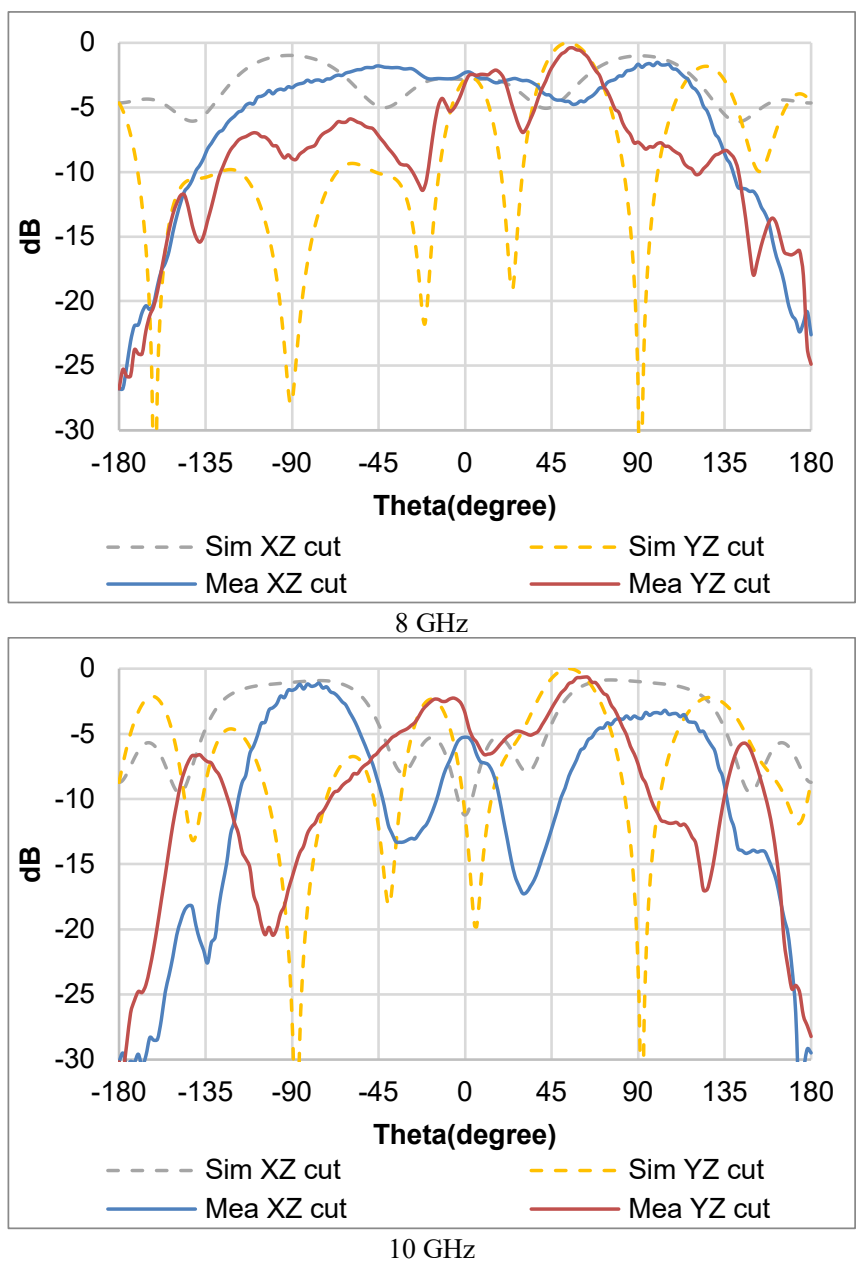

Fig. 19. Measured directivity patterns of 3D printed meshed monopole antenna at $4,6,8$ and $10 \mathrm{GHz}$, compared with the simulated radiation patterns.

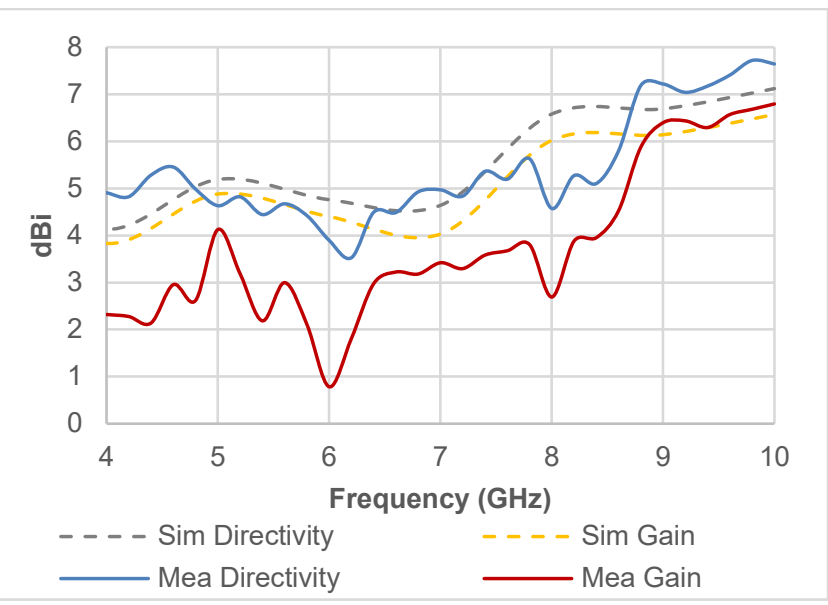

Fig. 20. Measured realised gain and directivity from 4 to 10 $\mathrm{GHz}$

\section{Conclusion}

This paper has investigated a wideband circular monopole on the human body and analyzed the detailed tradeoff between proximity to the human body with the S11 and efficiency as a function of frequency. The antenna demonstrated that it was resilient to different positions 
relative to the body as would be the case with a loose-fitting $\mathrm{T}$-shirt. Moving away from the antenna or operating at higher frequencies improved the efficiency. A meshed version of the monopole was designed which had a very similar performance in terms of S11 and efficiency but used less metallic material. The meshed design was realized by using embroidery and 3D printing techniques. Embroidered antenna was flexible and potentially could be integrated into fabric clothes. The embroidered version was not as well matched as the simulated design. This was due to the transmission line being composed of multiple threads as opposed to a continuous line. The 3D printed monopole had superior performance compared with the embroidered version because of the rigid substrate and higher conductivity of $3 \mathrm{D}$ printed silver material. Simulation results showed that embroidering this design might reduce the efficiency to approximately two thirds of the copper equivalent version both in free space and on the body.

\section{Acknowledgements}

This paper was in part supported by EPSRC grant SYnthesizing 3D METAmaterials for RF, microwave and THz applications (SYMETA) (EP/N010493/1).

\section{References}

[1] A. Tsolis, W. G. Whittow, A. A. Alexandridis, and J. C. Vardaxoglou, "Embroidery and related manufacturing techniques for wearable antennas: Challenges and opportunities," Electronics, vol. 3, no. 2, pp. 314-338, 2014.

[2] T. Acti et al., "Embroidered Wire Dipole Antennas Using Novel Copper Yarns," IEEE Antennas and Propagation Wireless Letters, vol. Submitted, pp. 14, 2014.

[3] J. Lilja, P. Salonen, T. Kaija, and P. de Maagt, "Design and Manufacturing of Robust Textile Antennas for Harsh Environments," IEEE Transactions on Antennas and Propagation, vol. 60, no. 9, pp. 4130-4140, Sep. 2012.

[4] A. Chauraya et al., "Inkjet printed dipole antennas on textiles for wearable communications," IET Microwaves, Antennas \& Propagation, vol. 7, no. 9, pp. 760-767, Jun. 2013.

[5] B. Gupta, S. Sankaralingam, and S. Dhar, "Development of wearable and implantable antennas in the last decade: A review," in 10th Mediterranean Microwave Symposium, 2010, pp. 251-267.

[6] Y. Ouyang and W. J. Chappell, "High frequency properties of electro-textiles for wearable antenna applications," Antennas and Propagation, IEEE Transactions on, vol. 56, no. 2, pp. 381-389, 2008.

[7] P. Salonen, Y. Rahmat-Samii, M. Schaffrath, and M. Kivikoski, "Effect of textile materials on wearable antenna performance: a case study of GPS antennas," IEEE Antennas and Propagation Society Symposium, no. 1, pp. 459-462, 2004.

[8] S. Zhu and R. Langley, "Dual-band wearable textile antenna on an EBG substrate," Antennas and Propagation, IEEE Transactions on, vol. 57, no. 4, pp. 926-935, 2009.

[9] B. Sanz-Izquierdo, F. Huang, and J. C. Batchelor, "Small size wearable button antenna," in First European Conference on Antennas and Propagation (EuCAP), 2006, pp. 1-4.

[10] L. Ma, R. M. Edwards, and W. G. Whittow, "A notched hand wearable ultra wideband $\mathrm{W}$ printed monopole antenna for sporting activities," in Loughborough Antennas and Propagation Conference (LAPC), 2008, pp. 397-400.

[11] A. Cihangir et al., "Feasibility study of $4 \mathrm{G}$ cellular antennas for eyewear communicating devices," IEEE Antennas and Wireless Propagation Letters, vol. 12, no. DOI: 10.1109/LAWP.2013.2287204, pp. 1704 1707, 2013.

[12] B. Sanz-Izquierdo, J. C. Batchelor, and M. I. Sobhy, "Compact UWB Wearable Antenna," in Loughborough Antennas and Propagation Conference (LAPC), 2007, pp. 121-124.

[13] T. Kaufmann and C. Fumeaux, "Wearable Textile Half-Mode Substrate-Integrated Cavity Antenna Using Embroidered Vias," IEEE Antennas and Wireless Propagation Letters, vol. 12, pp. 805-808, 2013.

[14] M. Ehteshami, V. Sathi, and N. Ehteshami, "Experimental investigation of a circularly polarised flexible polymer/composite microstrip antenna for wearable applications," IET Microwaves, Antennas \& Propagation, vol. 6, no. 15, pp. 1681-1686, Dec. 2012.

[15] R. Moro, S. Agneessens, H. Rogier, and M. Bozzi, "Circularly-polarised cavity-backed wearable antenna in SIW technology," IET Microwaves, Antennas \& Propagation, vol. 12, no. 1, pp. 127-131, Jan. 2018.

[16] Z. Hamouda, J. Wojkiewicz, A. A. Pud, L. Kone, S. Bergheul, and T. Lasri, "Flexible UWB organic antenna for wearable technologies application," IET Microwaves, Antennas \& Propagation, vol. 12, no. 2, pp. 160-166, Feb. 2018.

[17] A. K. Skrivervik, A. A. Moreira, and M. Koohestani, "System fidelity factor evaluation of wearable ultrawideband antennas for on-body communications," IET Microwaves, Antennas \& Propagation, vol. 9, no. 10, pp. 1054-1058, Jul. 2015.

[18] T. I. Yuk, Y. Sun, and S. W. Cheung, "Design of a textile ultra-wideband antenna with stable performance for body-centric wireless communications," IET Microwaves, Antennas \& Propagation, vol. 8, no. 15, pp. 1363-1375, Dec. 2014.

[19] A. Chauraya et al., "Addressing the challenges of fabricating microwave antennas using conductive threads," in 6th European Conference on Antennas and Propagation (EuCAP), 2012, pp. 1365-1367.

[20] S. Zhang et al., "Embroidered wearable antennas using conductive threads with different stitch spacings," in Loughborough Antennas \& Propagation Conference (LAPC), 2012, pp. 1-4.

[21] S. Zhang et al., "Embroidered Wearable Antennas Using Conductive Threads with Different Stitch Spacings," in Loughborough Antennas \& Propagation Conference (LAPC), 2012. 
[22] W. Whittow, C. Panagamuwa, R. Edwards, and J. Vardaxoglou, "Specific absorption rates in the human head due to circular metallic earrings at $1800 \mathrm{MHz}$," in 2007 Loughborough Antennas and Propagation Conference, 2007, pp. 277-280.

[23] W. G. Whittow, R. M. Edwards, C. J. Panagamuwa, and J. C. Vardaxoglou, "Effect of tongue jewellery and orthodontist metallic braces on the SAR due to mobile phones in different anatomical human head models including children," in 2008 Loughborough Antennas and Propagation Conference, 2008, pp. 293-296.

[24] C. J. Panagamuwa, W. G. Whittow, R. M. Edwards, and J. C. Vardaxoglou, "A study of the effects of metallic pins on SAR using a specific anthropomorphic mannequin (SAM) head phantom," in The Second European Conference on Antennas and Propagation (EuCAP 2007), 2007.

[25] P. M. Rayner and W. G. Whittow, "Specific absorption rate and efficiency of a wideband wearable monopole antenna near the human body," in Loughborough Antennas \& Propagation Conference, 2017.

[26] J. Krupka, W. Gwarek, N. Kwietniewski, and J. G. Hartnett, "Measurements of Planar Metal - Dielectric Structures Using Split-Post Dielectric Resonators," IEEE Transactions On Microwave Theory And Techniques, vol. 58, no. 12, pp. 3511-3518, 2010.

[27] S. Zhang, R. Seager, A. Chauraya, W. Whittow, and Y. Vardaxoglou, "Non-uniform Meshed Microstrip Antennas for Wearable Applications," in Antennas and Propagation (EuCAP), 8th European Conference, 2014.

[28] S. Zhang, W. Whittow, R. Seager, A. Chauraya, and J. C. Vardaxoglou, "Non-uniform mesh for embroidered microstrip antennas," IET Microwaves, Antennas \& Propagation, vol. 11, no. 8, pp. 10861091, Jun. 2017.

[29] Voxel8, "Working with the Conductive Silver Ink \& Solvent.".

[30] S. Zhang, W. Whittow, and J. (Yiannis) C. Vardaxoglou, "Additively manufactured artificial materials with metallic meta-atoms," IET Microwaves, Antennas \& Propagation, vol. 11, no. 14, pp. 1955-1961, Nov. 2017. 